\title{
Interactive comment on "The portable ice nucleation experiment PINE: a new online instrument for laboratory studies and automated long-term field observations of ice-nucleating particles" by Ottmar Möhler et al.
}

Anonymous Referee \#2

Received and published: 23 September 2020

Recommendation: minor revision

A new laboratory instrument for INP measurement called "portable Ince Nucleation Experiment" (PINE) chamber is introduced in this manuscript. The design, working principles, and operational procedures of the PINE chamber are described in details, as well as preliminary results from the HyICE campaign, AIDA intercomparison and SGP-ExINP long-term measurements are provided as work cases in the paper.

The development of the PINE chamber is a great contribution to the INP research 
field in specific and the Atmospheric science in general. It also provides long-term monitoring capability to operation-oriented organizations. The topic fits AMT scope perfectly. The paper is well organized and written. After the authors address my minor points, it should be in good shape for publication on AMT.

Minor comments:

The font on many figures is too small.

Line 175: remove "and"

Line 265: What is the aerosol size range for these concentrations?

Lines 271 to 275 : Is the assumption of ice saturated condition at the beginning of expansion reasonable? The response of the OPC does agree with this assumption. But is it universally valid?

Line 287: "larger than the dense"

Figure 6: Can a turbulence be introduced to the chamber to mix the air so that the temperature is more uniform across the chamber?

Line 446: replace "largest" with "highest".

Line 468: Based on Fig. 12, the minimum INP concentration is about $0.02 \mathrm{~L}-1$, not 0.2 L-1.

There are multiple places stating that details on HyICE results and SGP-ExINP results will be discussed in details in future papers. Can reduce the redundancy.

Interactive comment on Atmos. Meas. Tech. Discuss., doi:10.5194/amt-2020-307, 2020.

Discus: 